\title{
THE PROCESS OF COPULATION IN ORNITHODORUS MOUBATA.
}

\author{
By GEORGE H. F. NUTTALL, F.R.S. AND \\ GORDON MERRIMAN.
}

(From the Quick Laboratory, University of Cambridge.)

(With one Text-Figure.)

Although the literature on ticks is very extensive, we have failed to find any satisfactory description therein of the process of copulation. Most authors state that the male mouthparts are introduced into the female genital orifice, or vulva, and that this constitutes copulation, leaving it to the reader's imagination to determine how the seminal secretion gains access to the female generative organs. The mechanism of copulation, in other words, remains to be described, and we propose, in this paper, to give an account of what we have observed in Ornithodorus moubata. We shall describe the process in Ixodidae in a later paper, but may state here that, as far as our knowledge goes, it is essentially the same as in moubata, that is, impregnation takes place by means of spermatophores.

We have repeatedly observed the process in moubata in Cambridge, and the description which follows is based on the study of several pairs in copulation. When a male and female moubata, which are ready to copulate, are placed in a dish, the male creeps about upon the female and presently seeks to creep beneath her, usually to one side between the second and third legs. The posterior part of the female's body is now raised, and the male advances so as to bring his body into line with the female's, the ventral surfaces of the pair being apposed. The male clings with his legs to the basal joints of the female's legs, his pair I in 
front of pair I of the female, and pair II in front of pair II of the female, and so on. The male all the while feels about with his mouthparts for the female's genital orifice.

The process that follows can, with careful handling of the ticks, be most conveniently observed by placing the pair in a pit made with the end of a pencil in a ball of modelling-wax (plasticine). The ball may measure an inch or more in diameter, and can be rolled about to the desired position, being fixed there at any moment by slight pressure against the glass dish in which it is contained. The female always

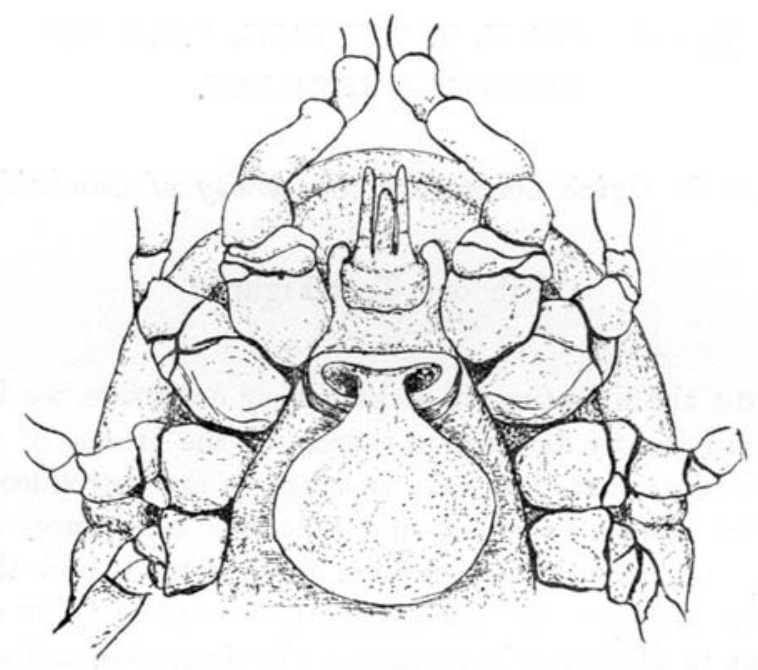

Fig. 1. Ornithodorus moubata, $q$. Showing the emptied portion of the spermatophore with the neck-shaped portion attached within the female sexual orifice. Drawn with the aid of a camera lucida (G. M. del.).

seeks to regain her natural position upon a horizontal surface, so it is necessary to immobilize her sufficiently to prevent this without harnpering the male. This can be done by modelling the wax about the edge of the pit so that it holds the female in place. Observations on free pairs shows that this manipulation, if done carefully, in no way interferes with the process. All of our observations were made with the aid of a Zeiss binocular microscope which can be inclined at any desired angle.

The male, having found the female's genital orifice by feeling about with his mouthparts, immediately introduces all of these (hypostome, 
chelicerae and palps) together into the orifice. The mouthparts are pushed in and withdrawn with a sawing motion, the capitulum being alternately protruded and retracted from his body whilst it is directed backward almost at a right angle to the long axis of the male's body. The mouthparts penetrate more and more deeply but not further than the basal article of the palps. At each movement of partial withdrawal the male mouthparts are tilted forward so that friction against the anterior lip of the vulva takes place. The chelicerae are all the while being actively protruded and retracted within their transparent sheaths, the distance which they travel in their movement to and fro corresponding about to the length of the second palpal article; the chelicerae usually move alternately. Presently the male capitulum is more and more depressed so that the hypostome points slightly backward whilst the dorsal surface of the basis capituli comes to be placed on a line traversing the first pair of coxae about midway along their length when viewed ventrally. (When disturbed at this stage it is seen that the male and female sexual apertures are in apposition.) The ventral surface of the female, together with the thicklipped vulva, has, up to this, been somewhat prominent, but now the area about the vulva, and especially posterior to it between the first pair of coxae, becomes markedly depressed. At the moment when the female venter becomes depressed the male withdraws his mouthparts completely from the vulva and at the same time separates his body somewhat from that of the female to which it has hitherto been closely applied. The male's capitulum is now directed forward, whilst the palps and chelicerae are working actively, the digits being moved about rapidly. (When the sexes are separated at this stage it is found that the spermatophore is issuing from the male sexual orifice. The spermatophore, viewed as a whole, is flask-shaped, with a long thin neck, which is the first part to issue from the orifice; the tip of the neck of the flask when it issues adheres to the tip of the male hypostome. The spermatophore is ejected rapidly and lies along the venter of the female with the neck directed toward the vulva into which it is immediately inserted by the hypostome of the male. A moment later a large amount of clear-watery fluid emerges from the coxal glands of the male.) When viewed from in front, the ticks not being disturbed, a large amount of clear fluid now floods the space between their venters; the male reintroduces his mouthparts into the vulva, and the ticks again bring their bodies close together. The male mouthparts are worked to and fro very much as they were at first, and, 
after two or three minutes, they are finally withdrawn and the male abandons the female.

The ventral surface of the female is found bathed with coxal secretion, the depression about the vulva has disappeared, and the collapsed spermatophore is found attached to the vulva with its neck pushed into the vagina. The whole process of copulation lasts about 15 minutes from the moment that the male inserts his mouthparts for the first time.

The spermatophore, immediately after it has been expelled by the male, appears as a smooth, glistening, very flexible body completely filled with slightly milky contents. (On one occasion when the male was disturbed and the spermatophore was found doubled up on the venter of the female, the spermatophore literally shot out its long thin neck when touched with a fine camel's hair brush in the effort to remove it uninjured.) The end of the neck of the spermatophore appears closed and rounded, whereas the expanded portion of the spermatophore is usually bilobed. When the ticks separate without interference the spermatophore neck appears shorter and the flask collapsed, and somewhat spoon-shaped with the concavity on the side where the male's body had rested upon it whilst in coitu. The neck of the spermatophore is firmly attached within the vagina and force is required to remove it; on seizing the spermatophore with a fine forceps the female can be lifted by it without rupturing the structure. On exerting more force the neck of the flask tears loose at the point of entrance into the vagina and the "mouth" of the spermatophore appears spread out and frayed. The full spermatophore is crowded with "prospermiums" and secretion rich in granules; when almost collapsed, a few male elements may still be found therein. The spermatophore, very soon after coitus has taken place, contracts, flattens and hardens, the edges of the "spoon" remaining upturned. We possess several females in our collection which have died or been preserved, with usually one, but at times two or even three empty spermatophores still adhering. The flask-like covering of the spermatophore is exceedingly tough, and tested with $10 \%$ caustic potash, it is found to be composed of chitin. The freshly expelled spermatophore, with fully extended neck, measures about 3 to $3.5 \mathrm{~mm}$. in length and about $1.7 \mathrm{~mm}$. in width at the widest part. When dried and attached to a female, to whom it may remain attached for some days, or even for weeks, it measures about $1.6 \mathrm{~mm}$. in length.

Although there are several points still to be elucidated with regard to this interesting process, we consider that what we have observed explains in the main how coitus takes place. The introduction of 
the male mouthparts necessarily dilates the female sexual orifice and doubtless excites the female. It is possible that a sticky secretion is given off by the male mouthparts which serves to attach the neck of the spermatophore so that its contents are fully voided into the vagina. The male brings his sexual aperture practically into apposition with that of the female, and when she is ready for impregnation, he withdraws his mouthparts and expels the spermatophore which issues with the neck directed forward so that it adheres to the tip of his hypostome and is promptly pushed into the vagina. The male removes his venter from that of the female so as to give space for the spermatophore to pass, and the female venter at the same time becomes concave for the same purpose. The flood of secretion from the male coxal glands serves to prevent the too rapid diging of the chitinous envelope of the spermatophore and keeps it highly flexible until its contents have been discharged -this may be especially necessary in such ticks as 0 . moubata which live in arid climates. The male reintroduces his mouthparts so as to "plant" the neck of the spermatophore in the vagina and he appears to rupture the tip of the spermatophore so that the contents escape into the spermatheca when the bodies of the ticks are brought together again closely and press upon the spermatophore, thus pumping out its contents.

Judging from the fact that we have not as yet observed empty spermatophores adhering to the external genitalia of female ticks belonging to other species, we must conclude that in other cases the spermatophores are introduced in toto into the spermatheca. This may be the case in $O$. savignyi, for Christophers (1906, p. 42) states that he found the "spermatozoa" (prospermiums) in this species "included in cyst-like spermatophores" within the spermatheca of the female. He figures two such spermatophores of savignyi and also flask-shaped spermatophores in the spermatheca of Rhipicephalus sanguineus. Christophers found spermatozoa in the oviducts of $O$. savignyi. Samson (1909, p. 186) has made a suggestive observation on Ixodes ricinus, which indicates that copulation takes place in an analogous manner in this species; she merely states, without giving any particulars, that the male impregnates the female by means of spermatophores. In this species, Bertkau (1881, p. 147) and Samson (1909 a, p. 216) have found that the spermatozoa pass up from the spermatheca into the ovaries and there fertilize the eggs. We have also observed them in this situation. Samson (1909 b, p. 495) states that the spermatozoa in O. moubata only attain their full development in the ovary. 
We have dwelt thus at length upon the process of copulation in O. moubata, because until now it has never been understood how the male impregnates the female.

As bearing on the process of copulation in Ixodidae we would add the following remarks:

We have stated elsewhere that the genus Ixodes (group Prostriata) is widely separated from the other genera of Ixodidae (group Metastriata) in important points of anatomical structure. In Ixodes the anal grooves surround the anus in front, the sexes show marked dimorphism in respect to the structure of the hypostome, and in certain species the sexes are frequently found coupling upon the host. In Ixodes the male inserts his mouth-parts into the female sexual orifice as a part of the sexual act. In none of the Metastriata has a similar method of coupling been observed; here the males remain attached for longer periods to the host and they do not appear to wander about upon it as do some species of Ixodes whose males infest the host together with the females. In Metastriata the females and males are found attached to the host so that in many cases the venters of the sexes are apposed.

We have discovered that in the Metastriata (including the genera Haemaphysalis, Dermucentor, Rhipicentor, Rhipicephalus, Boophilus, Margaropus, Hyalomma, Amblyomma and Aponomma) all the males possess a chitinous apron or flap covering the sexual aperture. The apron arises from the integument anteriorly to the sexual aperture and is directed backward over the aperture; it is frequently serrated along its rounded posterior border which is free. The apron can be readily lifted by inserting a fine needle between it and the body surface; it is very thin at the free margin, whereas it grows gradually thicker toward its origin. The apron is absent or rudimentary in the females.

Now we find that in Ixodes the males do not show an apron, or it is very rudimentary in character. On the other hand the apron, though very thin, may be very well developed in the females; is best seen in young specimens.

The presence of the apron in the males of Metastriata and its absence in 1xodes is very suggestive, and, taken together with the other differences, indicates that copulation may possibly take place in another manner in the Metastriata to what it does in Ixodes. The mechanism of copulation in Metastriata still remains to be determined and the significance of the apron requires to be explained. 


\section{REFERENCES.}

Bertkad, Pн. (1881). Bruchstuicke aus der Lebens, namentlich Fortpflanzungsgeschichte unserer Zecke, Ixodes ricinus. Verhandlungen des naturhsstorischen Vereines der preussischen Rheinlande und Westfalens, Jahrg. 38, Sitzungsberichte, pp. 145-148 (Bonn).

Christophers, S. R. (1906). The Anatomy and Histology of Ticks. Scientific Memoirs by Officers of the Medical and Sanitary Dep'ts of the Gov't of India (Calcutta). N.S. No. 23, 55 pp., Plates I-VI.

Samson, K. (1909a). Zur Anatomie und Biologie von Ixodes ricinus L. Zeitschr. f. wiss. Zool., xcIII. pp. 185-236, 4 plates, 18 text-figs.

SAMson, K. (1909 b). Zur Spermohistiogenese der Zecken. Sitzungsber. d. Gesellsch. naturf. Freunde, No. 8, pp. 486-499, Pl. IX, 7 text-figs. 